\title{
Antipsychotics in the treatment of autism
}

\author{
David J. Posey, Kimberly A. Stigler, Craig A. Erickson, and Christopher J. McDougle
}

Christian Sarkine Autism Treatment Center, Department of Psychiatry, Indiana University School of Medicine, Indianapolis, Indiana, USA.

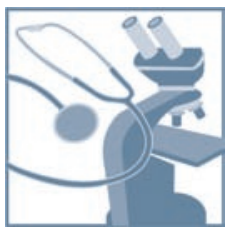

\begin{abstract}
Atypical antipsychotics have become indispensable in the treatment of a variety of symptoms in autism. They are frequently used to treat irritability and associated behaviors including aggression and self injury. They may also be efficacious for hyperactivity and stereotyped behavior. This review presents the rationale for the use of this drug class in autism and reviews the most important studies published on this topic to date. Significant adverse effects, including weight gain and the possibility of tardive dyskinesia, are reviewed. Future research directions are discussed.
\end{abstract}

Autistic disorder (autism) is a neurodevelopmental disorder that causes lifelong impairment in socialization, communication, and behavior. A number of specific core symptoms are found to varying degrees. These include poor eye contact, deficits in other nonverbal social behaviors, social withdrawal, impaired social reciprocity, echolalia, motor stereotypies, intense and circumscribed interests, and a preoccupation with parts of objects instead of the whole. These core impairments can range from mild to disabling and are qualitatively different from the more general delays that occur in mental retardation or primary language disorders. Autism is often associated with mental retardation, which contributes to impairment in functioning. The signs and symptoms of autism are usually recognized in early childhood. However, milder degrees of autism and other pervasive developmental disorders (PDDs; often called autism spectrum disorders) might go unrecognized or mislabeled until later in childhood or even adulthood.

The cause of autism is unknown. Evidence from twin and family studies indicates that autism is highly heritable. However, no single autism susceptibility gene has been consistently demonstrated to be important in a majority of cases (1). Neurochemical investigations have identified abnormalities in monoamines, glutamate, $\gamma$-amino hydroxybutyrate, and neuropeptides (2). Functional neuroimaging studies are beginning to demonstrate differences between the brains of persons with autism and those of controls (3). Brain regions potentially involved in autism and related disorders are diverse and include the cerebellum (4), fusiform gyrus (5), amygdala (6), and prefrontal cortex. No biological markers have been found to reliably diagnose autism in an individual patient.

\section{Diagnosis of different PDD subtypes}

The Diagnostic and statistical manual of mental disorders, fourth edition (7), provides specific criteria for the 5 subtypes of PDD, which include autism, Asperger's disorder, childhood disintegrative disorder (CDD), Rett's disorder, and PDD not otherwise specified (NOS). PDD subtypes differ by the age of onset, presence of regression, and degree of impairment in cognition, socialization, communication, and behavior (Table 1). Recent epidemiologic studies have found prevalence estimates of about 1 in 150 when all sub-

Nonstandard abbreviations used: ABC, Aberrant Behavior Checklist; CGI-I, Clinical Global Impression-Improvement; DA, dopamine; EPS, extrapyramidal symptoms; 5-HT, 5-hydroxytryptamine; HVA, homovanillic acid; NOS, not otherwise specified; PDD, pervasive developmental disorder; RUPP, Research Units on Pediatric Psychopharmacology; TD, tardive dyskinesia.

Conflict of interest: The authors have declared that no conflict of interest exists. Citation for this article: J. Clin. Invest. 118:6-14 (2008). doi:10.1172/JCI32483. types of PDD are included (8). Rett's disorder and CDD, which differ greatly from the other PDDs in terms of their diagnostic workup and clinical course, are rare. Because of this, subjects with these disorders are often excluded from clinical research focused on autism spectrum disorders. Most clinical trials of therapeutic agents have focused on autism alone or have included more heterogeneous samples of persons with autism, Asperger's disorder, and PDD NOS.

In addition to the hallmark features of PDD, affected persons frequently suffer from a variety of other neuropsychiatric symptoms and behaviors including anxiety, irritability, aggression, and hyperactivity. Using standardized parent and teacher questionnaires, Lecavalier examined the prevalence of these behavioral problems in 487 youths (aged 3-21 years) receiving special education for a PDD and found that approximately $50 \%$ of students with PDD had moderate or severe behavioral problems (9).

Behavioral interventions, including applied behavior analysis (ABA), are often used in addressing behavioral problems in youths with autism. Prior to behavioral intervention, an initial behavioral assessment, called a functional analysis, is performed. Functional analyses are controlled observational sessions that are conducted to objectively determine the primary motivating factor for the child's behavior, which may include seeking attention, accessing a preferred item, avoiding a task, or other inherently rewarding attributes of the behavior. Despite the success of behavioral interventions for reducing maladaptive behavior in individual children with autism, timely access to personnel and therapists trained in this intervention is often limited.

When behavioral interventions are not fully effective, medication-based treatments are often considered. A survey of psychotropic drug use in children with PDD found that approximately half of subjects are currently being prescribed a psychotropic drug and that $16.5 \%$ are taking an antipsychotic drug (10). Most commonly, antipsychotics are used in alleviating mood and behavioral disturbances characterized by irritability, aggression, and agitation. Recently, risperidone was approved by the U.S. FDA for the treatment of irritability in children and adolescents with autism. This approval is noteworthy because this is the first drug approved for use in autism and the first atypical antipsychotic to be approved for use in children and adolescents. Studies suggest that roughly $30 \%$ of children and adolescents with PDD experience moderate to severe irritability that is often accompanied by aggression toward self and others (9).

Well before its FDA approval, the off-label use of risperidone and other atypical antipsychotics had become common in the 
Table 1

Characteristics of DSM-IV subtypes of PDD

\begin{tabular}{|c|c|c|c|c|c|}
\hline Characteristic & Autistic disorder & Asperger's disorder & CDD & Rett's disorder & PDD NOS \\
\hline Age at onset & $<3 y r$ & Variable & $2-10 \mathrm{yr}$ & 5-30 mo & Variable \\
\hline Presence of regression & Mild, in minority of patients & No & Yes & Yes & No \\
\hline Gender & $\mathrm{M} / \mathrm{F}$ ratio $4: 1$ & $\mathrm{M}>\mathrm{F}$ & $\mathrm{M}>\mathrm{F}$ & F primarily & $M>F$ \\
\hline Mental retardation & Present in majority & Absent in majority & Often severe & Often severe & Variable \\
\hline Social impairment & Yes & Yes & Yes & Yes & Yes \\
\hline Communication impairment & Yes & $\mathrm{No}^{\mathrm{A}}$ & Yes & Yes & Variable \\
\hline Restricted interests/repetitive behaviors & Yes & Yes & Yes & Yes & Variable \\
\hline
\end{tabular}

DSM-IV, Diagnostic and statistical manual of mental disorders, fourth edition (7); F, female; M, male; M>F, more males than females. APragmatic and/or social language may be impaired.

treatment of autism (11). Several published reports had suggested the clinical effectiveness of risperidone (12), and a randomized controlled trial of risperidone in adults with autism had already been published (13). Conventional antipsychotics, like haloperidol, became and continue to be used less frequently, although prior randomized controlled trials have shown that they too are efficacious in young children with autism (14). The randomized controlled trials of risperidone that were subsequently conducted $(15,16)$ have helped to better elucidate both the beneficial and the adverse effects of risperidone when treating children and adolescents with autism.

Most conventional and atypical antipsychotics are potent dopamine (DA) type 2 receptor antagonists (Figure 1). Second-generation or atypical antipsychotics differ from conventional antipsychotics in that they usually exhibit antagonism of serotonin (5-hydroxytryptamine [5-HT]) type $2 \mathrm{~A}$ receptors in addition to blocking DA (Figure 2). Individual antipsychotic drugs may also differ within class (i.e., conventional vs. atypical) in their relative potency of receptor subtype blockade, as well as side effect profile.

This review focuses on clinical investigations undertaken to study the effects of antipsychotics in autism. Clinical evidence implicating dysregulation of DA and 5-HT in the underlying pathophysiology of autism will be reviewed, as antipsychotics exert their primary action via these 2 neurotransmitter systems. Following this, we will review published clinical research examining the efficacy of antipsychotics in autism and other PDDs.

\section{DA neurotransmission}

The monoamine DA is integral to motor and cognitive functioning as well as hormone release (17). DA has several receptor subtypes $\left(D_{1}-D_{5}\right)$ that differ in their structure, action, and location. The evidence for DA being important in autism largely comes from treatment studies. Early research suggested that dopaminergic drugs (e.g., psychostimulants) worsened symptoms of autism (18, 19) and that DA-blocking drugs (e.g., conventional antipsychotics) were associated with improvement in symptoms (reviewed below). Despite these clinical findings, dopaminergic abnormalities have been inconsistently found in studies investigating the neurochemical basis of autism.

Studies examining plasma and urine concentration of DA and homovanillic acid (HVA), the primary DA metabolite, have generally found no significant differences between autistic subjects and controls $(20,21)$. However, it is important to note that only approximately $25 \%$ of urine and plasma HVA appears to result from central DA turnover and that peripheral measures are primar- ily able to identify only large alterations in central DA metabolism (22). Most $(23,24)$, but not all (25), studies of CSF HVA levels in autism have also not found significant abnormalities in autism.

Genetic studies of DA involvement in autism have also been published. In a case-control study, the prevalence of the A1 allele of the $\mathrm{DA} \mathrm{D}_{2}$ receptor was significantly increased in the group with autism (26). In a second, sibling-pair study, there was no increased concordance for DA- $\beta$-hydroxylase (the enzyme that converts DA to norepinephrine) alleles in affected siblings (27). However, the mothers of autistic children had a higher frequency of alleles containing a 19-base pair deletion (which lowers serum DA- $\beta$-hydroxylase activity), and the authors hypothesized that this might alter the intrauterine environment in such a way to increase the risk of autism in genetically susceptible offspring.

Dopaminergic activity has also been investigated via neuroimaging. Using the PET tracer $\left[{ }^{18} \mathrm{~F}\right]$ fluorodopa (FDOPA), Ernst and colleagues (28) studied 14 children with autism and 10 control children. In the autistic group, regional FDOPA accumulation in the anterior medial prefrontal cortex was reduced by $39 \%$. In another study using PET, 6 children (aged 3-5 years) with autism were treated with 6R-L-erythro-5,6,7,8,-tetrahydrobiopterin (R$\mathrm{BH}_{4}$ ), a cofactor for tyrosine hydroxylase in the biosynthetic pathway of DA (29). Study subjects were included only if the investigators found low levels of $\mathrm{R}^{-\mathrm{BH}_{4}}$ in the CSF. Prior to treatment, PET revealed increased DA $D_{2}$ receptor binding in the caudate and putamen as a whole. After treatment, a $10 \%$ decrease in $\mathrm{DA} \mathrm{D}_{2}$ receptor binding was observed. In addition, CSF levels of $\mathrm{R}^{-\mathrm{BH}_{4}}$ were significantly increased and all parents reported some benefit in social interaction.

\section{Serotonin neurotransmission}

Serotonin neurons are widely distributed throughout the mammalian brain. This neuronal system is one of the earliest to develop, and the turnover rate of 5-HT is higher in the immature mammalian brain than at any other time in life. Serotonin plays a critical role as a growth factor in the immature brain, directing both proliferation and maturation (30). Different subtypes of 5-HT receptors have been identified $\left(5-\mathrm{HT}_{1}-5-\mathrm{HT}_{7}\right)$; these differ in terms of structure, action, and location.

Initial studies on the pathophysiology of autism focused primarily on the 5-HT system. Schain and Freedman (31) found consistent elevations in whole-blood 5-HT in autistic children compared with controls. There were no discernible clinical differences in those autistic subjects with hyperserotonemia and those without. This finding of hyperserotonemia in approximately one-third of 


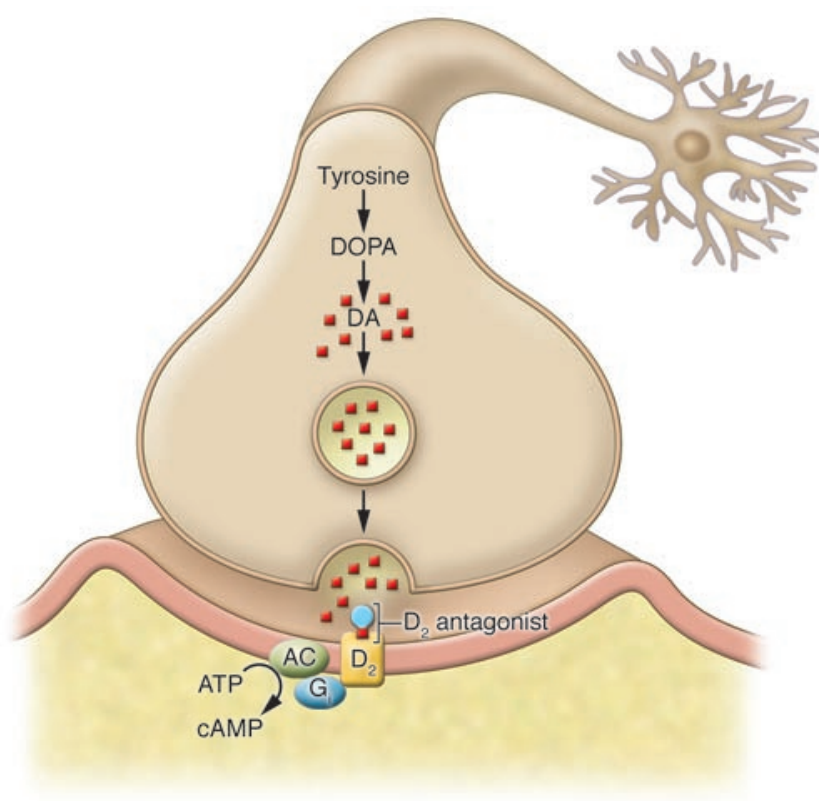

children with autism has been consistently replicated (32-34). Leboyer et al. (35) found age-related declines in whole-blood 5-HT in normal controls but not autistic subjects, which is thought to be suggestive of abnormal maturational processes of the 5-HT system in autism $(33,35)$.

Pharmacological challenge studies in response to 5-hydroxytryptophan (36) and fenfluramine (which boosts blood serotonin levels; ref. 37) point to diminished central 5-HT responsivity in subjects with autism. Examination of the effects of acute tryptophan (a dietary precursor of 5-HT) depletion in 17 drug-free adults with autism revealed an acute exacerbation of stereotyped and selfinjurious behavior (38).

A number of investigations of genes involved in the 5-HT system have been conducted in autism. The gene encoding the 5-HT transporter (SLC6A4), the site of action of serotonin reuptake inhibitors, has been considered a candidate gene for autism. Cook et al. (39) were the first to report the presence of an association between the short variant of a functional insertion-deletion polymorphism in the promoter region of SLC6A4 and autism. In contrast, Klauck et al. (40) identified preferential transmission of the long variant of this polymorphism in their sample of autistic subjects. Preliminary investigations have also sought a relationship between a subset of autistic subjects with prominent rigid-compulsive behaviors and 5-HT transporter with encouraging results $(41,42)$.

Neuroimaging studies of the 5-HT system have also been completed in autism. The first investigation used PET to assess the tracer $\alpha-\left[{ }^{11} \mathrm{C}\right]$ methyl-L-tryptophan (AMT) as an indicator of 5-HT synthesis in 8 autistic children and 5 of their siblings (43). Gross asymme-

\section{Figure 2}

Simplified schematic of a serotonin (5-HT) synapse showing synthesis of 5-HT, a postsynaptic 5- $\mathrm{HT}_{2}$ receptor, and intracellular mechanisms. In contrast to conventional antipsychotics, most atypical antipsychotics block $5-\mathrm{HT}_{2}$ receptors. The $5-\mathrm{HT}_{2}$ receptor is coupled by a $\mathrm{G}$ protein $\left(G_{q}\right)$ to phospholipase C (PLC). Phospholipase C hydrolyzes membrane-bound phosphatidyl inositol $\left(\mathrm{PIP}_{2}\right)$, generating 2 secondary messengers, inositol triphosphate $\left(\mathrm{IP}_{3}\right)$ and diacylglycerol (DAG).

\section{Figure 1}

Simplified schematic of a DA synapse showing synthesis of DA, a postsynaptic $D_{2}$ receptor, and intracellular mechanisms. Most conventional and atypical antipsychotics block $D A D_{2}$ receptors. The $D_{2}$ receptor is coupled by an inhibitory $G$ protein $\left(G_{i}\right)$ to adenylyl cyclase $(A C)$, which converts ATP to CAMP, a secondary messenger.

tries of 5-HT synthesis in frontal cortex, thalamus, and cerebellum were found in all 7 of the autistic boys but not in the only female autistic subject. Such asymmetries were not identified in the frontal cortex or thalamus of the siblings. The investigators concluded that the focal abnormalities in AMT accumulation may represent either aberrant innervation by 5-HT terminals or altered function in anatomically normal pathways. A subsequent study by the same investigators (44), again using PET and AMT, found that for nonautistic children, 5-HT synthesis capacity was more than $200 \%$ that of adult values until the age of 5 years and then declined toward adult values. In autistic children, 5 -HT synthesis capacity increased gradually between 2 and 15 years of age to values 1.5 -fold those of adult normal values. It was concluded that humans undergo a period of high brain-5-HT synthesis capacity during childhood and that this developmental process is disrupted in autistic children.

\section{Conventional antipsychotics in autism}

In the decade spanning 1965-1975, several studies were published that examined the effects of many different conventional antipsychotics in heterogeneous groups of children that included subjects with autism. Several conventional antipsychotics were studied comparing one active drug with another. Drugs studied included chlorpromazine, trifluoperazine, thiothixene, trifluperidol, fluphenazine, and molindone. Because of the imprecise diagnoses and lack of standardized outcome measures (45), it is difficult to extrapolate these findings to treatment today.

Magda Campbell, who pioneered efforts to investigate these drugs in placebo-controlled trials in autism, chose to study haloperidol, a potent DA receptor blocker. Haloperidol was known to

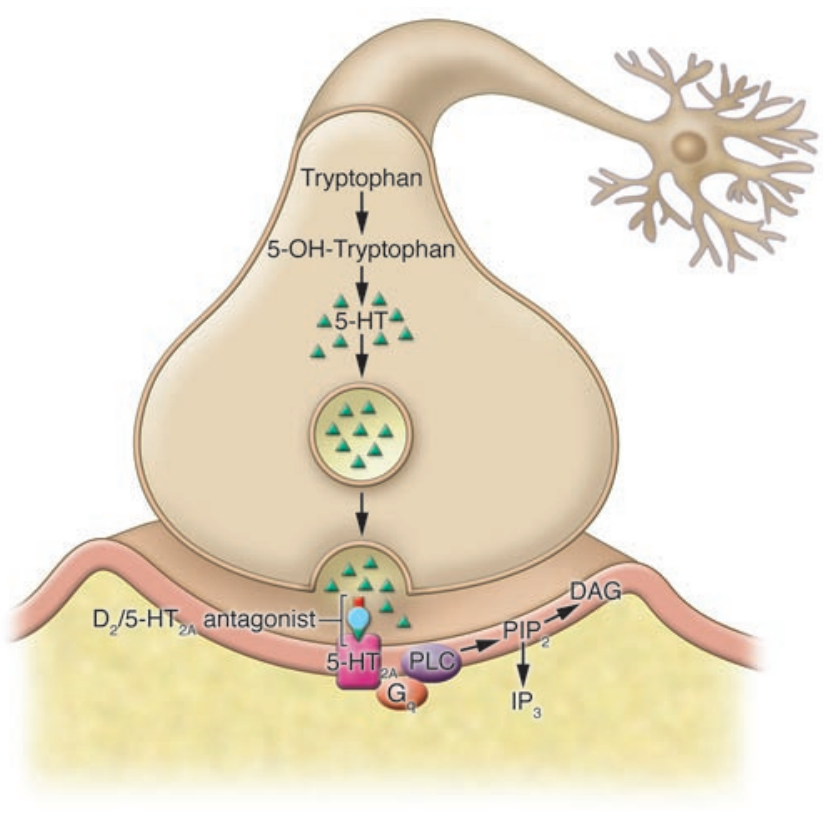




\section{Table 2}

Atypical antipsychotics commonly used to treat severe behavioral symptoms in PDDs

\begin{tabular}{|c|c|c|c|}
\hline Drug & Study (ref.) & Symptoms improved & Notable side effects \\
\hline \multicolumn{4}{|l|}{ Risperidone } \\
\hline & $2.9 \mathrm{mg} / \mathrm{d}$ > placebo in 31 adults with PDD (13) & $\begin{array}{l}\text { Aggression, irritability, } \\
\text { repetitive behavior }\end{array}$ & Sedation, weight gain \\
\hline & $1.8 \mathrm{mg} / \mathrm{d}>$ > placebo in 101 children with autism (15) & $\begin{array}{l}\text { Aggression, hyperactivity, } \\
\text { irritability, repetitive behavior }\end{array}$ & $\begin{array}{l}\text { Hypersalivation, } \\
\text { sedation, weight gain }\end{array}$ \\
\hline & $1.2 \mathrm{mg} / \mathrm{d}>$ placebo in 79 children with PDD (16) & $\begin{array}{l}\text { Aggression, hyperactivity, irritability, } \\
\text { repetitive language and behavior, } \\
\text { social withdrawal }\end{array}$ & Sedation, weight gain \\
\hline & $1 \mathrm{mg} / \mathrm{d}>$ placebo in 40 young children with PDD (69) & $\begin{array}{l}\text { Aggression, hyperactivity, nonverbal } \\
\text { communication, social responsiveness }\end{array}$ & Sedation, weight gain \\
\hline & $1.1 \mathrm{mg} / \mathrm{d}>$ placebo in 24 preschool children with PDD (70) & Mild improvement in autism severity & $\begin{array}{l}\text { Hypersalivation, } \\
\text { weight gain }\end{array}$ \\
\hline Olanzapine & $10 \mathrm{mg} / \mathrm{d}$ > placebo in 11 children with autism (74) & Global improvement & Sedation, weight gain \\
\hline Quetiapine & $\begin{array}{l}\text { No placebo-controlled studies; } 4 \text { open-label } \\
\text { investigations have reported } 22 \%-60 \% \text { response rate } \\
\text { (refs. } 75-78 ; N=6,9,20 \text {, and } 10 \text {, respectively) }\end{array}$ & Aggression, hyperactivity, inattention & $\begin{array}{l}\text { Agitation, sedation, } \\
\text { weight gain }\end{array}$ \\
\hline Ziprasidone & $\begin{array}{l}\text { No placebo-controlled studies; } 2 \text { open-label } \\
\text { investigations have reported } 50 \%-70 \% \text { response rate } \\
\text { (refs. } 80,81 ; N=12 \text { and } 10 \text {, respectively) }\end{array}$ & Aggression, irritability & $\begin{array}{l}\text { Sedation, weight gain } \\
\text { (mild) }\end{array}$ \\
\hline Aripiprazole & $\begin{array}{l}\text { No placebo-controlled studies; } 2 \text { open-label } \\
\text { investigations have reported } 92 \%-100 \% \text { response rate } \\
\text { (refs. } 84,85 ; N=5 \text { and } 13 \text {, respectively) }\end{array}$ & Aggression, irritability & Weight gain (mild) \\
\hline
\end{tabular}

$>$, more efficacious than.

be associated with less adverse cognitive effects and sedation than the low-potency antipsychotics. It was also faster acting (46) and associated with fewer extrapyramidal symptoms (EPS) (47) than another available high-potency antipsychotic, fluphenazine. In Campbell's first study, children with autism (aged 2.6-7.2 years) were randomized to haloperidol or placebo in combination with 1 of 2 different language training groups (14). The optimal dose of haloperidol was $1.7 \mathrm{mg} / \mathrm{d}$. Haloperidol was associated with significant improvement in withdrawal and stereotypy in children 4.5 years and older as assessed by the Children's Psychiatric Rating Scale (CPRS) (48). The addition of haloperidol to a behavioral intervention was associated with accelerated acquisition of imitative speech, suggesting that haloperidol might have some beneficial effects on learning when combined with behavioral treatment. Sedation was frequent (12 of 20 subjects) and dose related. An acute dystonic reaction occurred in 2 children. No adverse effects on cognition were detected using a standard cognitive battery. Subsequent studies were conducted that focused on symptom improvement as well as effects on learning. Positive effects on learning were found in some studies $(49,50)$, but not all $(51)$. Sedation and acute dystonic reactions were relatively common in these early studies of young children with autism.

One potential drawback of haloperidol is its propensity to cause dyskinesia. In a study of 60 children (aged 2.3-7.9 years) with autism, previous responders to haloperidol were enrolled in the study and randomized to 6 months of either continuous or discontinuous ( 5 days on, 2 days off) administration of haloperidol (52). After 6 months of haloperidol treatment, subjects were given placebo for 4 weeks. Three children developed dyskinesias during haloperidol treatment, while 9 others developed dyskinesias upon medication withdrawal; all dyskinesias were reversible.
Because of the high frequency of dyskinesias, tardive dyskinesia (TD) and withdrawal dyskinesia were followed prospectively in 118 autistic children (aged 2.3-8.2 years) who did not have a history of seizure disorder, preexisting dyskinesias, or an identifiable cause for their autism (e.g., fragile X syndrome or tuberous sclerosis). Subjects were assigned to cycles of 6 months of haloperidol treatment followed by 4 weeks of placebo (53). If haloperidol was still clinically indicated following 1 cycle of treatment, then subsequent treatment cycles took place. Dyskinesias developed in 40 children (33.9\%), although the majority of them were withdrawal dyskinesias and were reversible. In a subgroup of 10 children receiving a higher dose of haloperidol that averaged $3.4 \mathrm{mg} / \mathrm{d}$ at study exit (compared with $2.0 \mathrm{mg} / \mathrm{d}$ for the overall group), 9 (90\%) developed dyskinesias. In another subgroup of 9 children who developed TD, females were overrepresented. Preand perinatal complications were also more frequent in those that developed dyskinesias (54).

In summary, multiple studies have found haloperidol efficacious for improving a variety of behavioral symptoms in young children with autism. There is less robust evidence for the efficacy of the other conventional antipsychotics. Haloperidol treatment frequently leads to acute dystonic reactions, withdrawal dyskinesias, and TD. The high risk of EPS has limited the use of these medications to only the most treatment-refractory patients.

\section{Atypical antipsychotics in autism}

Antagonism at 5-HT receptors is thought to underlie, at least in part, the reported advantages of atypical antipsychotics over conventional agents, namely the reduced propensity to cause EPS (55). In addition, atypical antipsychotics are generally considered more effective than conventional antipsychotics for improving the 
negative symptoms of schizophrenia such as anhedonia, avolition, and apathy (56). These negative symptoms have similarities to the social impairment characteristic of autism. Therefore, the atypical antipsychotic risperidone was postulated to have potential efficacy for treating core symptoms in autism (57). As discussed below, these hopes have not been fully realized.

This section will review the atypical antipsychotics most commonly prescribed for autism. These include risperidone, olanzapine, quetiapine, ziprasidone, and aripiprazole (Table 2). Only a few case reports of clozapine treatment in autism have been published (58-60). Clozapine is rarely used clinically because it has the potential to cause life-threatening agranulocytosis and requires frequent weekly to biweekly venipuncture to monitor white blood cell counts. Cognitively impaired children and adults with high degrees of irritability frequently do not tolerate venipuncture well. Due to the absence of any known advantages to clozapine over other atypical antipsychotics for these symptoms, its use is limited.

Risperidone. The first placebo-controlled trial of risperidone conducted in autism involved 31 adults (mean age, 28.1 years) with autism or PDD NOS (13). Risperidone (mean dose, $2.9 \mathrm{mg} / \mathrm{d}$ ) was significantly more efficacious than placebo, with 8 of $14(57 \%)$ subjects being categorized as responders on the Clinical Global Impression-Improvement (CGI-I) scale versus 0 of 16 in the placebo group. Specifically, risperidone was efficacious for reducing interfering repetitive behavior as well as aggression toward self, others, and property. Significant differences between risperidone and placebo were not captured on scales measuring social relatedness to people and language. In 13 of 15 (87\%) subjects randomized to risperidone, at least one adverse effect was observed - although this included mild, transient sedation in 5 subjects - compared with 5 of 16 (31\%) subjects given placebo (agitation in all 5 cases). Weight gain occurred in a minority ( 2 of $14 ; 14 \%$ ) of risperidonetreated subjects and was significantly less than that reported in the pediatric trials discussed below.

A double-blind, placebo-controlled study of risperidone in children and adolescents with autism was completed by the Research Units on Pediatric Psychopharmacology (RUPP) Autism Network (15). A total of 101 children (mean age, 8.8 years) was randomly assigned to receive 8 weeks of risperidone or placebo. At baseline, all patients had significant irritability, aggression, or self injury as rated by an Aberrant Behavior Checklist (ABC) (61) Irritability subscale score of 18 or greater. Treatment with risperidone for 8 weeks (mean dose, $1.8 \mathrm{mg} / \mathrm{d}$ ) resulted in a $57 \%$ reduction in the Irritability subscale score of the $\mathrm{ABC}$ as compared with a $14 \%$ decrease in the placebo group. Of the risperidone-treated subjects, $69 \%$ were categorized as treatment responders, compared with $12 \%$ of those given placebo. Risperidone was associated with an average weight gain of $2.7 \mathrm{~kg}$, as compared with $0.8 \mathrm{~kg}$ with placebo. Drooling was more commonly reported with risperidone than placebo, but standardized measures of acute EPS and TD were not significantly different between groups.

The RUPP study (15) also examined the other 4 subscales of the $\mathrm{ABC}$, which included social withdrawal, stereotypy, hyperactivity, and inappropriate speech. Risperidone led to greater reduction on all these scales, but the reduction in social withdrawal and inappropriate speech were only significant at the $P=0.03$ level (not significant following Bonferroni correction for multiple analyses). To further analyze the efficacy of risperidone on the core symptoms of autism in this group of highly irritable patients, McDougle et al. (62) examined secondary outcome measures that included a modified Ritvo-Freeman Real Life Rating Scale (R-F RLRS) (63) and modified Children's Yale-Brown Obsessive Compulsive Scale (CY-BOCS) (64). On the R-F RLRS, significant improvement was seen on the following subscales: sensory motor behaviors, affectual reactions, and sensory responses. However, there was no significant change on the social relationship to people or language subscales. Risperidone was more efficacious than placebo in reducing interfering repetitive behavior on the CY-BOCS.

A companion study to the initial 8-week acute risperidone trial by the RUPP Autism Network has also been completed (65). In this study, 63 subjects who responded to 8 weeks of acute treatment continued on open-label risperidone for an additional 4 months. During this open-label continuation phase, the mean risperidone dose remained stable and there was no clinically significant worsening of target symptoms. Drug use was discontinued by 2 subjects (8\%) due to loss of efficacy and by 1 subject due to adverse effects. Subjects gained an average of $5.6 \mathrm{~kg}$ of body weight during the total 6-month course of risperidone treatment. Subsequently, 32 subjects who continued to be classified as responders after the 16-week extension were randomized to continued risperidone versus gradual substitution with placebo (over the course of 3 weeks). In subjects randomized to placebo, 10 of 16 (62.5\%) showed significant worsening of symptoms, compared with 2 of 16 subjects $(12.5 \%)$ who continued on risperidone, suggesting that risperidone treatment beyond 6 months is needed to prevent relapse. This relapse with drug withdrawal has also been confirmed in another placebocontrolled discontinuation study of risperidone in PDD (66).

A second multicenter, placebo-controlled study of risperidone in children with PDD has been conducted in Canada (16). A total of 79 children (mean age, 7.5 years) was randomized to either risperidone (mean dose, $1.2 \mathrm{mg} / \mathrm{d}$ ) or placebo for 8 weeks. No specific entry criteria were reported other than a diagnosis of PDD and a Childhood Autism Rating Scale (CARS) (67) score exceeding 30. However, the average baseline ABC Irritability subscale score of 20 suggests that these children were, on average, highly symptomatic at study entry. Risperidone was associated with a $64 \%$ reduction in $\mathrm{ABC}$ irritability subscale scores versus $31 \%$ in the placebo group. On the CGI-I, 21 of 40 (53\%) risperidone-treated subjects were "much" or "very much" improved compared with 7 of $39(18 \%)$ placebo-treated subjects. Significant improvement was seen on all subscales of the $\mathrm{ABC}(P<0.05)$, but the greatest magnitude of improvement was observed for irritability and hyperactivity. Social withdrawal decreased by $63 \%$ in the risperidone group compared with $40 \%$ for placebo $(P<0.01)$. Weight gain following 8 weeks of risperidone was $2.7 \mathrm{~kg}$ compared with $1.0 \mathrm{~kg}$ for placebo. EPS as measured by standardized rating scales were equal in both groups.

These 2 studies of risperidone in children with autism produced similar results in terms of efficacy and adverse events. These studies eventually led to FDA approval of risperidone for the treatment of irritability in children and adolescents with autism aged 5-16 years. In addition, there is evidence that risperidone is efficacious for hyperactivity, repetitive behavior, and perhaps social withdrawal in children with PDD exhibiting high levels of baseline irritability.

Other investigators have studied risperidone in samples that included even younger children. Risperidone is occasionally needed in very young children due to the severity of the irritability and agitation, which can be extreme (68). Nagaraj et al. (69) recently published a study that included children as young as 2 years using doses of $1 \mathrm{mg} / \mathrm{d}$. In this study of 40 children (aged 2-9 years), ris- 
peridone was highly efficacious as measured by ratings on the CARS and the Children's Global Assessment Scale. Luby et al. (70) also found some evidence for efficacy in a study of 24 children under the age of 6 years. However, these investigators found risperidone (dose range, $0.5-1.5 \mathrm{mg} / \mathrm{d}$ ) only minimally efficacious compared with placebo at 6 months, possibly owing to group differences at baseline or sample size. In this latter study, high degrees of irritability were not required for study entry. This too may have limited observed improvement.

Olanzapine. To date, 3 prospective open-label trials of olanzapine in PDD have been published. In a 12 -week study of olanzapine (mean dose, $7.8 \mathrm{mg} / \mathrm{d}$; dose range, $5-20 \mathrm{mg} / \mathrm{d}$ ) in children, adolescents, and adults (age range, 5-42 years) with autism and other PDDs, 6 of 8 (75\%) patients who entered a 12-week, open-label trial were responders based on the CGI-I (71). Significant improvements in overall symptoms of autism, motor restlessness/hyperactivity, social relatedness, affectual reactions, sensory responses, language usage, self injury, aggression, irritability or anger, anxiety, and depression were observed. Significant changes in repetitive behaviors did not occur for the group. The drug was generally well tolerated, with the most significant adverse effects being increased appetite and weight gain in 6 patients. The mean weight for the group increased $8.4 \mathrm{~kg}$ during the course of the 12 -week trial.

In another open-label study, 12 children with autism (mean age, 7.8 years) were randomized to 6 weeks of open-label treatment with olanzapine or haloperidol (72). Mean final dosages were $7.9 \mathrm{mg} / \mathrm{d}$ for olanzapine and $1.4 \mathrm{mg} / \mathrm{d}$ for haloperidol. In the olanzapine group, 5 of 6 (83\%) subjects were rated as responders; 3 of $6(50 \%)$ in the haloperidol group were rated as responders. Weight gain from baseline to the end of treatment was significantly higher in the olanzapine group (mean, $4.1 \mathrm{~kg}$ ) compared with the haloperidol group (mean, $1.5 \mathrm{~kg}$ ).

In a third study, 25 children (mean age, 11.2 years) with PDD were treated with olanzapine (mean dose, $10.7 \mathrm{mg} / \mathrm{d}$ ) for 3 months (73). In contrast to the other 2 studies, olanzapine was effective in only $3(12 \%)$ subjects. The reason for the lower response rate is unclear, but could have been the relatively low level of disruptive behavior at baseline. In this study, the mean baseline ABC Irritability subscale score was 11 , which is low compared with the baseline values in the 2 largest studies of risperidone in children with PDD: 20 and 26. The other 2 olanzapine investigations discussed above had specific entry criterion based on degree of disruptive behavior.

One small placebo-controlled study of olanzapine has been published (74). In this study, 11 patients with PDD were randomized to olanzapine (mean dose, $10 \mathrm{mg} / \mathrm{d}$ ) or placebo for 8 weeks. Of subjects receiving olanzapine, 3 of $6(50 \%)$ were judged treatment responders on the CGI-I, compared with 1 of 5 (20\%) subjects receiving placebo. Mean weight gain was 7.5 pounds compared with 1.5 for placebo.

Quetiapine. Four open-label studies or case series have reported on the use of quetiapine in treating PDD. In the first of these, 6 children and adolescents (aged 6-15 years) with autism were treated with quetiapine (mean dose, $225 \mathrm{mg} / \mathrm{d}$ ) during a 16-week openlabel trial (75). Quetiapine was poorly tolerated by 4 subjects, 3 of whom terminated early due to sedation and 1 due to a seizure. The 2 subjects who finished the study were classified as responders on the CGI-I. Increased appetite and weight gain were also reported. The investigators concluded that quetiapine was poorly tolerated and generally ineffective in this diagnostic group.
Another open-label trial of quetiapine in PDD enrolled 9 adolescents (aged 12-17 years) with autism (76). Subjects were treated with quetiapine (mean dose, $292 \mathrm{mg} / \mathrm{d}$ ) for 12 weeks. The trial was completed by 6 of 9 subjects (67\%), with 2 of 9 (22\%) judged responders on the CGI-I. Two subjects discontinued quetiapine early, 1 due to sedation and 1 to increased agitation/aggression. Overall, adverse effects reported for the group included sedation, weight gain, agitation, and aggression.

Retrospective studies published recently have been slightly more optimistic as to the efficacy of quetiapine in PDD. In 1 case series (77), 20 patients (aged 5-28 years) were treated with quetiapine (mean dose, $249 \mathrm{mg} / \mathrm{d}$ ) over an average of 60 weeks (range, 4-180 weeks). Of these 20 patients, 8 (40\%) were judged responders to quetiapine based on a CGI-I performed at the time of clinic visits. Adverse effects occurred in $50 \%$ of patients, but only led to drug discontinuation in $15 \%$ of cases.

In another case series (78), quetiapine (mean dose, $477 \mathrm{mg} / \mathrm{d}$ ) was effective in treating 6 of 10 (60\%) patients (aged 5-19 years) with PDD as judged by the CGI-I. Significant improvement was also found on the Conduct, Hyperactivity, and Inattention subscales of the Conners Parent Scale (79). Adverse effects were mild and included sedation, sialorrhea, and weight gain.

At first glance, the response rate in these uncontrolled studies of quetiapine is lower than that reported with risperidone. The highest response rate in any of these studies was $60 \%$. In the study by Hardan et al. (78), somewhat higher doses of quetiapine were reached compared with the other 3 studies. Controlled trials of quetiapine are needed to more accurately determine its efficacy and appropriate dosing in the treatment of autism and other PDDs.

Ziprasidone. There have been 2 published studies that examined the effectiveness of ziprasidone in PDD. In the first study (80), ziprasidone (mean dose, $59 \mathrm{mg} / \mathrm{d}$ ) was associated with "much" or "very much" improvement on the CGI-I in 6 of 12 (50\%) children and adolescents (mean age, 11.6 years) with PDD following an average treatment duration of 14 weeks. Improvement was seen in symptoms of aggression, agitation, and irritability. Transient sedation was the most common side effect. No cardiovascular side effects were observed. On average, patients lost weight during treatment with ziprasidone, but this could have been secondary to being switched from other drugs that had caused excessive weight gain. Mean change in body weight for the group was $-5.8 \pm 12.5$ pounds (range, -35 to 6 pounds): 5 patients lost weight, 5 had no change, 1 gained weight, and 1 had no follow-up weight beyond the baseline measure.

In the second study (81), 10 adults with autism and mental retardation living in a residential setting were switched to ziprasidone from other atypical antipsychotics (clozapine, risperidone, and quetiapine), most commonly because of excessive weight gain. At 6 months after the switch, they had lost a significant amount of weight, averaging 9.5 pounds. The changes in maladaptive behavior were not significantly different, and the authors reported that 6 patients improved, 1 was unchanged, and 3 decompensated. The potential for QTc interval prolongation with ziprasidone on electrocardiography led to a warning in the full prescribing information (82). The drug should not be given to individuals with cardiac arrhythmias or long QT syndrome or who take other medications that can prolong the QTc interval.

Aripiprazole. Aripiprazole is the newest atypical antipsychotic available in the United States. This drug differs from other atypicals because it is a partial DA $\mathrm{D}_{2}$ and $5-\mathrm{HT}_{1 \mathrm{~A}}$ agonist in addition 
to being a $5-\mathrm{HT}_{2 \mathrm{~A}}$ antagonist (83). In 1 case series (84), 5 patients (mean age, 12.2 years) received aripiprazole (mean dose, $12 \mathrm{mg} / \mathrm{d}$ ) for an average duration of 13 weeks. All 5 subjects (100\%) were deemed responders on the CGI-I. Significant improvement was noted in a variety of interfering behavioral symptoms, including aggression, self injury, and irritability. Aripiprazole was well tolerated. No acute EPS or changes in heart rate or blood pressure were recorded. Of the 5 subjects, 2 experienced mild transient somnolence. There was a reduction in average weight, but this may have been secondary to discontinuing a prior atypical antipsychotic drug that had caused significant weight gain.

Our group recently reported preliminary results from an ongoing open-label prospective study of aripiprazole in youth with Asperger's disorder and PDD NOS (85). All subjects initially received 1.25 $\mathrm{mg} / \mathrm{d}$ aripiprazole with flexible dosing during the first 6 weeks (to optimize response and tolerability) up to a maximum of $15 \mathrm{mg} / \mathrm{d}$. The dose was maintained at the optimal dose for the next 8 weeks of treatment. Outcome measures included the CGI-I and ABC. During this 14-week trial, 13 children and adolescents (mean age, 8.9 years) received aripiprazole (dose range, $2.5-15 \mathrm{mg}$; mean dose, $7.5 \mathrm{mg} / \mathrm{d})$. Of the 13 subjects, $12(92.3 \%)$ responded to treatment based on a CGI-I global score of "much" or "very much" improved and at least a $25 \%$ improvement on the ABC Irritability subscale. Aripiprazole was well tolerated. The mean weight gain was $1.2 \mathrm{~kg}$.

\section{Side effect considerations}

Weight gain. Weight gain is one of the most troublesome side effects of atypical antipsychotics when used in children and adolescents (86). It is especially concerning because obesity can set the stage for the development of serious medical problems including diabetes, hyperlipidemia, and cardiovascular disease. The available published evidence suggests that weight gain is greatest for clozapine and olanzapine and least for ziprasidone and aripiprazole (86). The weight gain occurring with risperidone and quetiapine appears to be intermediate. However, it should be emphasized that this assessment is based on average weight gain. There are some individuals who do not gain excessive weight on these drugs and others who gain weight even on "weight-neutral" atypical antipsychotics.

Children may be at greatest risk for this side effect, but little research has been done comparing weight gain between children and adults (87). In a study of children with autism from the RUPP Autism Network, weight gain was most prominent during the first 8 weeks of treatment and decelerated over the subsequent 4 months of risperidone treatment (88). Serum leptin levels at 8 weeks did not predict weight gain at the end of the study, suggesting that elevated leptin is likely not a causal mechanism for atypical antipsychotic-induced weight gain in this population.

Given the likelihood for these medications to cause weight gain, it is very important to educate patients and their families about this adverse effect. In addition, regular monitoring of weight is also important. Given that weight gain can precede the development of diabetes and hyperlipidemia, periodic monitoring of fasting blood glucose and lipid profiles is also advisable.

Hyperprolactinemia. The RUPP Autism Network measured serum prolactin levels in their studies of risperidone in children with autism (89). Prolactin measurements were obtained at baseline, 8 weeks, 6 months, and 18 months. Risperidone was associated with a 4 -fold increase in prolactin at 8 weeks, but tended to decrease at 6 and 18 months. For those subjects treated with risperidone for 18 months, the prolactin level was $25.3 \pm 15.6 \mathrm{ng} / \mathrm{ml}$ (compared with $10.4 \pm 10.1 \mathrm{ng} / \mathrm{ml}$ at baseline). Interestingly, despite elevations in serum prolactin levels, there were no reported side effects or changes on physical exam typically associated with hyperprolactinemia (e.g., gynecomastia, galactorrhea). However, this could be secondary to the subject sample, which was predominantly male and prepubertal. These subjects may be less likely to experience these side effects than postpubertal females. Similar findings for prolactin have been found in using risperidone to treat children and adolescents with disruptive behavior disorders (90).

EPS. EPS are common when using haloperidol in the treatment of children with autism. Fortunately, the available data suggest that the atypical antipsychotics are less likely to cause EPS. In the studies of risperidone done by the RUPP Autism Network (15), standardized measures of acute EPS (using the Simpson-Angus Rating Scale; ref. 91) and TD (using the Abnormal Involuntary Movement Scale; ref. 92) were not different between risperidone and placebo (93). Indeed, overall rates of any side effect elicited by a structured checklist that could have been EPS were low and often comparable to placebo. The one exception to this was drooling, which was more commonly reported in children treated with risperidone $(P=0.04)$. Research is needed on the frequency of EPS with other atypical antipsychotics in this diagnostic population. In addition, currently available studies have not addressed the long-term risk of TD.

Sedation and adverse cognitive effects. Antipsychotics are frequently associated with sedation, especially early in the course of treatment. In the RUPP Autism Network study of risperidone (93), 37\% of risperidone-treated subjects experienced moderate or severe sedation compared with $12 \%$ of subjects treated with placebo. Sedation markedly declined after $6-8$ weeks of treatment. Studying the cognitive effects of risperidone has been challenging in autism owing to testing difficulties in a study population characterized by irritability and communication difficulties. Preliminary placebo-controlled studies have not found adverse cognitive effects of risperidone in children with autism (94) or in children with intellectual disabilities (95).

\section{Summary and future directions}

Both haloperidol and risperidone have been shown to be efficacious for treating several of the behavioral symptoms associated with autism. The current role of haloperidol is limited due to the risk of EPS, especially TD. Because of this, atypical antipsychotics are more commonly used today in treating persons with autism. Despite the efficacy of risperidone, the decision to prescribe this drug needs to include consideration of the potential side effects, especially those of weight gain, hyperprolactinemia, and TD. Treatment with other drug classes, including anticonvulsants, antidepressants, and stimulants, can occasionally lead to reductions in aggression and irritability in autism. However, the efficacy of these other medications for this specific symptom cluster has not been clearly demonstrated (96).

Despite its efficacy for reducing behavioral symptoms, it is unclear whether risperidone improves the core social and communication impairment of autism. Indeed, a study that included less irritable children (70) found a lower rate or magnitude of response. Additional studies of risperidone and other atypical antipsychotics in nonirritable children with autism or studies using other measures of social impairment might be informative. It also remains to be determined whether atypical antipsychotics other than risperidone are effective in the treatment of disruptive 
behavior in autism. Large placebo-controlled studies of olanzapine and aripiprazole are underway. The long-term significance of hyperprolactinemia, as well as the long-term risk of TD, needs to be determined in either prospectively defined cohorts or via larger controlled studies of longer duration. Finally, further research that informs the clinical management of weight gain occurring with these drugs when used in autism is needed. This might include identifying patients who are genetically more susceptible to this side effect as well as determining the best approach to management (e.g., diet and/or exercise, switching drugs, or pharmacologic treatments).

\section{Acknowledgments}

This work was supported in part by a Department of Housing and Urban Development grant (B-01-SP-IN-0200; to C.J. McDougle); by a Research Unit on Pediatric Psychopharmacology - Psychosocial Intervention grant (U10 MH066766) from the National Institute of Mental Health (NIMH), to Indiana University (C.J. McDougle, K.A. Stigler, and D.J. Posey); by a Young Investigator Award (Seaver Investigator) from the National Alliance for Research on Schizophrenia and Depression (to D.J. Posey); by a Daniel X. Freedman Psychiatric Research Fellowship Award (to K.A. Stigler); and by a Career Development Award (K23 MH068627) from the NIMH (to D.J. Posey). We also thank Jennifer McCarthy for assistance with manuscript preparation.

Address correspondence to: David J. Posey, Department of Psychiatry, Indiana University School of Medicine, Riley Hospital, Room 4300, 702 Barnhill Dr., Indianapolis, Indiana 46202, USA. Phone: (317) 274-8162; Fax: (317) 278-0609; E-mail: dposey@iupui.edu.
1. Muhle, R., Trentacoste, S.V., and Rapin, I. 2004. The genetics of autism. Pediatrics. 113:e472-e486.

2. McDougle, C.J., Erickson, C.A., Stigler, K.A., and Posey, D.J. 2005. Neurochemistry in the pathophysiology of autism. J. Clin. Psychiatry. 66(Suppl. 10):9-18.

3. DiMartino, A., and Castellanos, F.X. 2003. Functional neuroimaging of social cognition in pervasive developmental disorders: a brief review. Ann. N. Y. Acad. Sci. 1008:256-260.

4. Allen, G., Müller, R., and Courchesne, E. 2004. Cerebellar function in autism: functional magnetic resonance image activation during a simple motor task. Biol. Psychiatry. 56:269-278.

5. Schultz, R.T., et al. 2000. Abnormal ventral temporal cortical activity during face discrimination among individuals with autism and Asperger syndrome. Arch. Gen. Psychiatry. 57:331-340.

6. Sweeten, T.L., Posey, D.J., Shekhar, A., McDougle, C.J. 2002. The amygdala and related structures in the pathophysiology of autism. Pharmacol. Biochem. Behav. 71:449-455.

7. American Psychiatric Association. 1994. Diagnostic and statistical manual of mental disorders. 4th edition. American Psychiatric Publishing Inc. Arlington, Virginia, USA. 886 pp.

8. Autism and Developmental Disabilities Monitoring Network Surveillance Year 2002 Principal Investigators, and Centers for Disease Control and Prevention. 2007. Prevalence of autism spectrum disorders--autism and developmental disabilities monitoring network, 14 sites, United States, 2002. MMWR Surveill. Summ. 56:12-28.

9. Lecavalier, L. 2006. Behavioral and emotional problems in young people with pervasive developmental disorders: relative prevalence, effects of subject characteristics, and empirical classification. J. Autism Dev. Disord. 36:1101-1114.

10. Aman, M.G., Lam, K.S.L., and Van Bourgondien, M.E. 2005. Medication patterns in patients with autism: temporal, regional, and demographic influences. J. Child Adolesc. Psychopharmacol. 15:116-126.

11. Witwer, A., and Lecavalier, L. 2005. Treatment incidence and patterns in children and adolescents with autism spectrum disorders. J. Child Adolesc. Psychopharmacol. 15:671-681.

12. Posey, D.J., and McDougle, C.J. 2000. The pharmacotherapy of target symptoms associated with autistic disorder and other pervasive developmental disorders. Harv. Rev. Psychiatry. 8:45-63.

13. McDougle, C.J., et al. 1998. A double-blind, placebo-controlled study of risperidone in adults with autistic disorder and other pervasive developmental disorders. Arch. Gen. Psychiatry. 55:633-641.

14. Campbell, M., et al. 1978. A comparison of haloperidol and behavior therapy and their interaction in autistic children. J. Am. Acad. Child Psychiatry. 17:640-655.

15. Research Units on Pediatric Psychopharmacology
Autism Network. 2002. Risperidone in children with autism and serious behavioral problems. New Engl. J. Med. 347:314-321.

16. Shea, S., et al. 2004. Risperidone in the treatment of disruptive behavioral symptoms in children with autistic and other pervasive developmental disorders. Pediatrics. 114:e634-e641.

17. Moore, R.Y., and Bloom, F.E. 1979. Central catecholamine neuron systems: anatomy and physiology of the norepinephrine and epinephrine systems. Ann. Rev. Neurosci. 2:113-168.

18. Campbell, M., et al. 1972. Response to triiodothyronine and dextroamphetamine: a study of preschool schizophrenic children. J. Autism Child Schizophr. 2:343-358.

19. Campbell, M., et al. 1976. Levodopa and levoamphetamine: a crossover study in young schizophrenic children. Curr. Ther. Res. Clin. Exp. 19:70-86.

20. Launay, J.M., et al. 1987. Catecholamine metabolism in infantile autism: a controlled study of 22 autistic children. J. Autism Dev. Disord. 17:333-347.

21. Minderaa, R.B., et al. 1989. Neurochemical study of dopamine functioning in autistic and normal subjects. J. Am. Acad. Child Adolesc. Psychiatry. 28:200-206.

22. Maas, J.W., Hattox, S.E., Greene, N.M., and Landis, D.H. 1980. Estimates of dopamine and serotonin synthesis by the awake human brain. J. Neurochem. 34:1547-1549.

23. Narayan, M., Srinath, S., Anderson, G.M., and Meundi, D.B. 1993. Cerebrospinal fluid levels of homovanillic acid and 5-hydroxyindoleacetic acid in autism. Biol. Psychiatry. 33:630-635.

24. Ross, D.L., Klykylo, W.M., and Anderson, G.M. 1985. Cerebrospinal fluid indoleamine and monoamine effects in fenfluramine treatment of autism. Ann. Neurol. 18:394.

25. Gillberg, C., and Svennerholm, L. 1987. CSF monoamines in autistic syndromes and other pervasive developmental disorders of early childhood. $\mathrm{Br} . \mathrm{J}$. Psychiatry. 151:89-94.

26. Comings, D.E., et al. 1991. The dopamine D2 receptor locus as a modifying gene in neuropsychiatric disorders. JAMA. 266:1793-1800.

27. Robinson, P.D., Schutz, C.K., Macciardi, F., White, B.N., and Holden, J.J. 2001. Genetically determined low maternal serum dopamine $\beta$-hydroxylase levels and the etiology of autism spectrum disorders. Am. J. Med. Genet. 100:30-36.

28. Ernst, M., Zametkin, A.J., Matochik, J.A., Pascualvaca, D., and Cohen, R.M. 1997. Low medial prefrontal dopaminergic activity in autistic children. Lancet. 350:638.

29. Fernell, E., et al. 1997. Possible effects of tetrahydrobiopterin treatment in six children with autism - clinical and positron emission tomography data: a pilot study. Dev. Med. Child Neurol. 39:313-318.

30. Whitaker-Azmitia, P.M. 1993. The role of serotonin and serotonin receptors in development of the mammalian nervous system. In Receptors in the developing nervous system. Volume 2: Neurotransmitters. I.S. Zagon and P.J. McLaughlin, editors. Chapman \& Hall. London, United Kingdom. 43-53.

31. Schain, R.J., and Freedman, D.X. 1961. Studies on 5-hydroxyindole metabolism in autistic and other mentally retarded children. J. Pediatr. 58:315-320.

32. Ritvo, E.R., et al. 1970. Increased blood serotonin and platelets in early infantile autism. Arch. Gen. Psychiatry. 23:566-572.

33. Anderson, G.M., et al. 1987. Whole blood serotonin in autistic and normal subjects. J. Child Psychol. Psychiatry. 28:885-900.

34. McBride, P.A., et al. 1998. Effects of diagnosis, race, and puberty on platelet serotonin levels in autism and mental retardation. J. Am. Acad. Child Adolesc. Psychiatry. 37:767-776.

35. Leboyer, M., et al. 1999. Whole blood serotonin and plasma beta-endorphin in autistic probands and their first-degree relatives. Biol. Psychiatry. 45:158-163.

36. Hoshino, Y., et al. 1984. Serotonin metabolism and hypothalamic-pituitary function in children with infantile autism and minimal brain dysfunction. Jpn. J. Psychiatry Neurol. 26:937-945.

37. McBride, P.A., et al. 1989. Serotonergic responsivity in male young adults with autistic disorder: results of a pilot study. Arch. Gen. Psychiatry. 46:213-221.

38. McDougle, C.J., et al. 1996. Effects of tryptophan depletion in drug-free adults with autistic disorder. Arch. Gen. Psychiatry. 53:993-1000.

39. Cook, E.H., et al. 1997. Evidence of linkage between the serotonin transporter and autistic disorder. Mol. Psychiatry. 2:247-250.

40. Klauck, S.M., Poustka, F., Benner, A., Lesch, K.P., and Poustka, A. 1997. Serotonin transporter (5-HTT) gene variants associated with autism? Hum. Mol. Genet. 6:2233-2238.

41. McCauley, J.L., et al. 2004. Linkage and association analysis at the serotonin transporter (SLC6A4) locus in a rigid-compulsive subset of autism. Am. J. Med. Genet. B Neuropsychiatr. Genet. 127:104-112.

42. Mulder, E.J., et al. 2005. Serotonin transporter intron 2 polymorphism associated with rigid-compulsive behaviors in Dutch individuals with pervasive developmental disorder. Am. J. Med. Genet. B Neuropsychiatr. Genet. 133:93-96.

43. Chugani, D.C., et al. 1997. Altered serotonin synthesis in the dentatothalamocortical pathway in autistic boys. Ann. Neurol. 42:666-669.

44. Chugani, D.C., et al. 1999. Developmental changes in brain serotonin synthesis capacity in autistic and nonautistic children. Ann. Neurol. 45:287-295.

45. Campbell, M., Geller, B., and Cohen, I.L. 1977. Current status of drug research and treatment with autistic children. J. Pediatr. Psychol. 2:153-161.

46. Faretra, G., Dooher, L., and Dowling, J. 1970. Comparison of haloperidol and fluphenazine in disturbed children. Am. J. Psychiatry. 126:1670-1673. 
47. Engelhardt, D.M., Polizos, P., Waizer, J., and Hoffman, S.P. 1973. A double-blind comparison of fluphenazine and haloperidol in outpatient schizophrenic children. J. Autism Child Schizophr. 3:128-137.

48. Fish, B. 1985. Children's Psychiatric Rating Scale (scoring). Psychopharmacol. Bull. 21:753-764.

49. Cohen, I.L., et al. 1980. Behavioral effects of haloperidol in young autistic children. An objective analysis using a within-subjects reversal design. J. Am. Acad. Child Adolesc. Psychiatry. 19:665-677.

50. Anderson, L.T., et al. 1984. Haloperidol in the treatment of infantile autism: effects on learn ing and behavioral symptoms. Am. J. Psychiatry. 141:1195-1202.

51. Anderson, L.T., et al. 1989. The effects of haloperidol on discrimination learning and behavioral symptoms in autistic children. J. Autism Dev. Disord. 19:227-239

52. Perry, R., et al. 1989. Long-term efficacy of haloperidol in autistic children: continuous versus discontinuous drug administration. J. Am. Acad. Child Adolesc. Psychiatry. 28:87-92.

53. Campbell, M., et al. 1997. Neuroleptic-related dyskinesias in autistic children: a prospective, longitudinal study. J. Am. Acad. Child Adolesc. Psychiatry. 36:835-843.

54. Armenteros, J.L., Adams, P.B., Campbell, M., and Eisenberg, Z.W. 1995. Haloperidol-related dyskinesias and pre- and perinatal complications in autistic children. Psychopharmacol. Bull. 31:363-369.

55. Pierre, J.M. 2005. Extrapyramidal symptoms with atypical antipsychotics: incidence, prevention and management. Drug Saf. 28: 191-208.

56. Chouinard, G., et al. 1993. A Canadian multicenter placebo-controlled study of fixed doses of risperidone and haloperidol in the treatment of chronic schizophrenic patients. J. Clin. Psychopharmacol. 13:25-40.

57. Fisman, S., and Steele, M. 1996. Use of risperidone in pervasive developmental disorders: a case series. J. Child Adolesc. Psychopharmacol. 6:177-190.

58. Zuddas, A., Ledda, M.G., Fratta, A., Muglia, P., and Cianchetti, C. 1996. Clinical effects of clozapine on autistic disorder (letter). Am. J. Psychiatry. 153:738.

59. Chen, N.C., Bedair, H.S., McKay, B., Bowers, M.B., Jr., and Mazure, C. 2001. Clozapine in the treatment of aggression in an adolescent with autistic disorder. J. Clin. Psychiatry. 62:479-480.

60. Gobbi, G., and Pulvirenti, L. 2001. Long-term treatment with clozapine in an adult with autistic disorder accompanied by aggressive behavior. J. Psychiatry Neurosci. 26:340-341.

61. Aman, M.G., Singh, N.N., Stewart, A.W., and Field, C.J. 1985. The aberrant behavior checklist: a behavior rating scale for the assessment of treatment effects. Am. J. Ment. Defic. 5:485-491.

62. McDougle, C.J., et al. 2005. Risperidone for the core symptom domains of autism: results from the study by the autism network of the Research Units on Pediatric Psychopharmacology. Am. J. Psychiatry. 162:1142-1148.

63. Freeman, B.J., Ritvo, E.R., Yakota, A., and Ritvo, A. 1986. A scale for rating symptoms of patients with the syndrome of autism in real life settings. J. Am.
Acad. Child Adolesc. Psychiatry. 25:130-136.

64. Scahill, L., et al. 1997. Children's Yale-Brown Obsessive Compulsive Scale: reliability and validity. J. Am. Acad. Child Adolesc. Psychiatry 36:844-852.

65. Research Units on Pediatric Psychopharmacology Autism Network. 2005. Risperidone treatment of autistic disorder: longer-term benefits and blinded discontinuation after 6 months. Am. J. Psychiatry. 162:1361-1369.

66. Troost, P.W., et al. 2005. Long term effects of risperidone in children with autism spectrum disorders: a placebo discontinuation study. J. Acad. Child Adolesc. Psychiatry. 44:1137-1144.

67. Schopler, E., Reichler, R.J., DeVellis, R.F., and Daly, K. 1980. Toward objective classification of childhood autism: Childhood Autism Rating Scale (CARS). J. Autism Dev. Disord. 10:91-103.

68. Posey, D.J., Walsh, K.H., Wilson, G., and McDougle, C.J. 1999. Risperidone in the treatment of two very young children with autism. J. Child Adolesc. Psychopharmacol. 9:273-276.

69. Nagaraj, R., Singhi, P., and Malhi, P. 2006. Risperidone in children with autism: randomized, placebocontrolled, double-blind study. J. Child Neurol. 21:450-455.

70. Luby, J., et al. 2006. Risperidone in preschool children with autistic spectrum disorders: an investigation of safety and efficacy. J. Child Adolesc. Psychopharmacol. 16:575-587.

71. Potenza, M.N., Holmes, J.P., Kanes, S.J., and McDougle, C.J. 1999. Olanzapine treatment of children, adolescents, and adults with pervasive developmental disorders: an open-label pilot study. J. Clin. Psychopharmacol. 19:37-44.

72. Malone, R.P., Cater, J., Sheikh, R.M., Choudhury, M.S., and Delaney, M.A. 2001. Olanzapine versus haloperidol in children with autistic disorder: an open pilot study. J. Am. Acad. Child Adolesc. Psychiatry. 40:887-894.

73. Kemner, C., Willemsen-Swinkels, S.H., de Jonge, M., Tuynman-Qua, H., and van Engeland, H. 2002. Open-label study of olanzapine in children with pervasive developmental disorder. J. Clin. Psychopharmacol. 22:455-460.

74. Hollander, E., et al. 2006. A double-blind placebocontrolled pilot study of olanzapine in childhood/ adolescent pervasive developmental disorder. J. Child Adolesc. Psychopharmacol. 16:541-548.

75. Martin, A., Koenig, K., Scahill, L., and Bregman, J. 1999. Open-label quetiapine in the treatment of children and adolescents with autistic disorder. J. Child Adolesc. Psychopharmacol. 9:99-107.

76. Findling, R.L., et al. 2004. Quetiapine in nine youths with autistic disorder. J. Child Adolesc. Psychopharmacol. 14:287-294.

77. Corson, A.H., Barkenbus, J.E., Posey, D.J., Stigler, K.A., and McDougle, C.J. 2004. A retrospective analysis of quetiapine in the treatment of pervasive developmental disorders. J. Clin. Psychiatry. 65:1531-1536.

78. Hardan, A.Y., Jou, R.J., and Handen, B.L. 2005. Retrospective study of quetiapine in children and adolescents with pervasive developmental disorders. J. Autism Dev. Disord. 35:387-391.

79. Goyette, C.H., Conners, C.K., and Ulrich, R.F.
1978. Normative data on revised Conners Parent and Teacher Rating Scales. J. Abnorm. Child Psychol. 6:221-236

80. McDougle, C.J., Kem, D.L., and Posey, D.J. 2002. Case series: use of ziprasidone for maladaptive symptoms in youths with autism. J. Am. Acad. Child Adolesc. Psychiatry. 41:921-927.

81. Cohen, S.A., Fitzgerald, B.J., Khan, S.R., and Khan, A. 2004. The effect of a switch to ziprasidone in an adult population with autistic disorder: chart review of naturalistic, open-label treatment. J. Clin. Psychiatry. 65:110-113.

82. Pfizer. 2007. Ziprasidone [package insert]. March revision. New York, New York, USA.

83. Burris, K.D., et al. 2002. Aripiprazole, a novel antipsychotic, is a high-affinity partial agonist at human dopamine $\mathrm{D}_{2}$ receptors. J. Pharmacol. Exp. Ther. 302:381-389.

84. Stigler, K.A., Posey, D.J., and McDougle, C.J. 2004. Case report: aripiprazole for maladaptive behavior in pervasive developmental disorder. J. Child Adolesc. Psychopharmacol. 14:455-463.

85. Stigler, K.A., et al. 2006. A prospective, open-label study of aripiprazole in youth with Asperger's disorder and pervasive developmental disorder not otherwise specified. Neuropsychopharmacology. 31:S194.

86. Stigler, K.A., Potenza, M.N., Posey, D.J., and McDougle, C.J. 2004. Weight gain associated with atypical antipsychotic use in children and adolescents: prevalence, clinical relevance, and management. Pediatric Drugs. 6:33-44.

87. Fedorow, V.J., and Fombonne, E. 2005. Metabolic side effects of atypical antipsychotics in children: a literature review. J. Psychopharmacol. 19:533-550.

88. Martin, A., et al. 2004. Weight and leptin changes among risperidone-treated youths with autism: 6-month prospective data. Am. J. Psychiatry. 161:1125-1127.

89. Anderson, G.M., et al. 2007. Effects of short- and long-term risperidone treatment on prolactin levels in children with autism. Biol. Psychiatry. 61:545-550.

90. Findling, R.L., et al. 2003. Prolactin levels during long-term risperidone treatment in children and adolescents. J. Clin. Psychiatry 64:1362-1369.

91. Simpson, G.M., and Angus, J.W. 1970. A rating scale for extrapyramidal side effects. Acta Psychiatrica Scandinavica. 212:11-19.

92. National Institute of Mental Health. 1985. Abnormal involuntary movement scale (AIMS). Psychopharmacol. Bull. 21:1077-1080.

93. Aman, M.G., et al. 2005. Acute and long-term safety and tolerability of risperidone in children with autism. J. Child. Adolesc. Psychopharmacol. 15:869-884.

94. Troost, P.W., et al. 2006. Neuropsychological effects of risperidone in children with pervasive developmental disorders: a blinded discontinuation study. J. Child Adolesc. Psychopharmacol. 16:561-573.

95. Pandina, G.J., et al. 2007. Risperidone and cognitive function in children with disruptive behavior disorders. Biol. Psychiatry. 62:226-234.

96. McDougle, C.J., Stigler, K.A., and Posey, D.J. 2003. Treatment of aggression in children and adolescents with autism and conduct disorder. J. Clin. Psychiatry. 64(Suppl. 4):16-25. 